\title{
Minority Tourist Information Service and Sustainable Development of Tourism under the Background of Smart City
}

\author{
Li Zhan ${ }^{1}$ and Kai Ning $\mathbb{C}^{2}$ \\ ${ }^{1}$ School of Geography and Tourism, Harbin University, Harbin 150080, Heilongjiang, China \\ ${ }^{2}$ Harbin Vocational College of Science and Technology, Harbin 150300, Heilongjiang, China \\ Correspondence should be addressed to Kai Ning; ningkai@hrbu.edu.cn
}

Received 25 August 2021; Revised 11 October 2021; Accepted 22 October 2021; Published 19 November 2021

Academic Editor: Sang-Bing Tsai

Copyright (c) $2021 \mathrm{Li}$ Zhan and Kai Ning. This is an open access article distributed under the Creative Commons Attribution License, which permits unrestricted use, distribution, and reproduction in any medium, provided the original work is properly cited.

\begin{abstract}
The continuous and in-depth development of smart technology has brought new development opportunities and challenges to the development of the tourism industry. This research mainly discusses the design of ethnic minority tourism information services and sustainable tourism development in the context of smart cities. The smart tourism public service application system must meet the three major requirements of different service objects. One is a smart service system aimed at satisfying tourists' travel information services. The second is to meet the needs of tourism companies for online marketing and e-commerce on the platform. The third is to provide a platform for the government to master travel information and supervise the travel market to realize e-government management. Therefore, the smart tourism application system includes three aspects: service, market, and management. The smart tourism service module is a module that the platform provides tourists with "eating, accommodation, transportation, travel, shopping, and entertainment" tourism information inquiry and consulting services and also uses modern information technology to provide navigation, tour guide, and shopping guide services in tourism. The smart tourism marketing module is the corporate product display, image promotion, and platform sales services provided by the platform for tourism companies. The smart tourism management module provides tourism management departments with services for managing various types of tourism information on the platform, platform security operations, and emergency response systems. As an ethnic minority region, the total tourism revenue of $\mathrm{M}$ city in 2020 will reach 75.68 billion yuan, a year-on-year increase of $21.33 \%$. This research will highlight the unique charm of ethnic minorities and help drive the economic development of one party.
\end{abstract}

\section{Introduction}

Ethnic minorities have formed a unique cultural system in the long history and radiate their own unique attraction and unique style. One of the important strategies for developing a cultural tourism platform is to display the most representative and characteristic culture of ethnic minorities through the platform, to dig deep into the cultural customs, and to let tourists appreciate the beauty of ethnic minorities.

In the context of the rapid advancement of information technology and the upsurge of smart city construction, this study sorts out the current situation and problems of ethnic minority tourism information service systems, analyzes tourists' evaluation and demand for ethnic minority tourism information services, and provides new ideas for the transformation and upgrading of tourism cities. It also lists some domestic cities as typical cases, analyzes the construction practices of ethnic minority tourism information service systems in the process of smart city construction, finds out the shortcomings, and gives countermeasures and suggestions. It has important theoretical exploration and practical guidance value.

The development of global tourism puts forward new requirements for the construction of smart tourism. Mohamad $\mathrm{M}$ believes that more and more tourism-related data have reached the level of $\mathrm{TB}$ or even $\mathrm{PB}$, which brings great difficulties to tourism management. His research is not innovative [1]. Nenkov identified the requirements for 
human resource development. At the same time, according to the economic methodology that describes human resource development as a circular process, an appropriate human resource development management system is determined. His research lacks data [2]. Cheng believes that recently, TODIM, which can represent the psychological behavior of decision makers under risk, has been introduced to deal with the multiattribute decision-making (MADM) problem. In addition, the binary language term set is an effective tool to describe the uncertainty of MADM problems. He extends the TODIM method to MADM with 2meta language information. He begins with a brief introduction to the definition and distance of binary language information and walks through the steps of the classic TODIM method to solve the MADM problem. Then, based on the classical TODIM method, he proposed an extended TODIM method to deal with the MADM problem of attribute values in binary language information, so his research is not sufficient [3]. Wei proposed the overall design of industrial information service platform based on tourism big data. His research focuses on the overall function, data source, data standard, and application scope of the platform [4]. Ashari believes that one of the biggest attractions of Bandung's tourism industry is nature tourism. Restrictions on obtaining information about Bandung's nature tourism still exist, as there are new attractions in Bandung every year. This is especially true for foreign tourists outside of Bandung. Tourists are still confused about finding new and popular tourist attractions, and these places are worth visiting. He did not further explore the economic value of tourism $[5,6]$. Filda believes that tourism loyalty is created through the good quality of tourism services and the availability of tourism products. His research discusses various attributes of tourism service quality, namely travel agents, efficient people, accessible transportation, and information service quality. Except for the impact of tourism service quality on the loyalty of Indonesian tourists, other assumptions in his research are inconclusive [7]. Setiorini studies and analyzes the grammatical errors in the spoken English of customer service in Malang Tourism Information Center. The purpose of his research was to determine what types of errors customer service said were made and why. These data were collected from four customer service offices by recording their conversations with tourists, and his research data were too small [8].

This research mainly discusses the design of ethnic minority tourism information services and sustainable tourism development in the context of smart cities. The smart tourism public service application system must meet the three major requirements of different service objects. One is a smart service system aimed at satisfying tourists' travel information services. The second is to meet the needs of tourism companies for online marketing and e-commerce on the platform. The third is to provide a platform for the government to master travel information and supervise the travel market to realize e-government management. Therefore, the smart tourism application system includes three aspects: service, market, and management.

\section{Research Methods}

2.1. Smart City. Smart cities are built on the basis of digital cities, inheriting IBM's wisdom concept, and use advanced information technology to enable citizens, enterprises, governments, and institutions to communicate and operate more conveniently and efficiently. The intelligent city construction basically complies with a certain pattern, combining the advantages of the city's own current situation and long-term development plan and the building of three systems from the bottom up: the basic and intermediate exchange layers, and the middle and upper application layers. This will change the traditional outward operating service mode of various roles so that we can realize the intelligence of life, life production, and life managing.

Because the information has the characteristics of comprehensiveness, timeliness, systematicness, relevance, accessibility, and accuracy, the ability and level of tourism information service not only affect the overall marketing effect of a tourism destination but also related to the quality of its tourism reception service. Finally, it affects the shaping of tourism destination image and the overall development of tourism. The evaluation index of accessibility is $[9,10]$

$$
R=\int_{i=1}^{n} \frac{T}{n}
$$

Among them, $i$ stands for tourist attractions and $T$ stands for a certain point in the area. The calculation formula of vegetation coverage in tourist area is [11]

$$
f=\frac{D_{1}-D_{\text {soil }}}{D_{\text {vog }}-D_{\text {soil }}} .
$$

Among them, $f$ represents the vegetation coverage rate. The biological abundance index calculated according to the relevant weights is [12]

$$
S_{z}=A \times(0.35 f+0.21 g+0.11 c+0.04 b+0.01 u)
$$

where $S_{z}$ stands for biological abundance index. The degree of disturbance of human activities to the landscape can also be used to characterize the fragmentation of the landscape at a specific time and nature $\mathrm{PH}[13]$.

$$
\mathrm{PH}=\frac{N}{A} \text {. }
$$
[14]

The comprehensive comfort index of the scenic spot is

$$
S=0.6 \times|t-10|+0.7 \times|f-10|+0.5 \times|n-10| .
$$

Among them, $t$ represents the comprehensive comfort index. The calculation method of ecological footprint is [15]

$$
E=\mathrm{NF}=N \sum_{i=1}^{n} r a .
$$

Among them, NF represents the total ecological footprint. Ecological carrying capacity represents its ability to update people's needs [16]. 


$$
E=\mathrm{Ne}=N \sum_{i=1}^{n} \operatorname{Ary}=\frac{Y_{1}}{Y_{2}} .
$$

The ecological deficit of scenic spots reflects the difference between the ecological carrying capacity and ecological footprint of a region or country [17].

$$
\begin{aligned}
E & =E_{F}-E_{C}=N\left(e_{f}-e_{c}\right), \\
\varphi^{2} & =R(M-1) \varphi .
\end{aligned}
$$

For the tourist ecological footprint [18]:

$$
\begin{aligned}
\mathrm{EF}_{T} & =\mathrm{ER}, \\
\text { ef } & =\frac{\mathrm{EF}_{T}}{N_{T}} .
\end{aligned}
$$

Among them, $\mathrm{EF}_{T}$ and ef, respectively, represent the total tourist ecological footprint and total ecological footprint of the area. The ratio between the two variables is expressed as follows [19]:

$$
\beta=\frac{\operatorname{cov}(X, Y)}{\sigma_{X} \sigma_{Y}}=\frac{E(X Y)-E(X) E(Y)}{\sqrt{E\left(X^{2}\right)-E^{2}(X) \sqrt{E\left(Y^{2}\right)-E^{2}(Y)}}} .
$$

\subsection{Ethnic Minority Smart Tourism Service Platform}

2.2.1. Overall Framework. Taking various tourism data as information resources, tourists as the center, and using various information technologies and intelligent terminals, the intelligent tourism service platform for ethnic minorities provides tourism information services, tourism transaction services, and tourism decision-making release for tourists, enterprises, and governments in the whole process of tourism, providing convenient ways and intelligent means for various tourism public services.

The Minority Smart Tourism Service Platform is a public service channel based on the standardization of data and information, collecting, processing, exchanging and sharing tourism service information, providing tourism service applications as the main body, and improving the quality of tourism public services as the ultimate goal of public service channels. In the perspective of the requirement analysis of the intelligent tourism service platform for ethnic minorities and with the overall design framework, the overall framework design of the intelligent tourism service platform for ethnic minorities includes that there are five parts: exhibition application layer, core business application layer, application support the application support layer, data resource layer, and infrastructure level.

The calculation formula for the scores of the original $p$ variables on the $k$ principal components is [20]

$$
z_{i}=e_{r} x_{1}+e_{2} x_{2}+\cdots+\operatorname{ex}_{p} .
$$

The specific form is [21]

$$
\begin{aligned}
R & =\left[\begin{array}{ccc}
z_{11} & z_{12} & z_{1 n} \\
\ldots & \ldots & z_{2 n} \\
z_{p 1} & \ldots & z_{p k}
\end{array}\right], \\
M & =\frac{\sum_{i=1}^{n} T^{2}+M N(n+1)}{M N\left(N^{2}+1\right)} .
\end{aligned}
$$

Consistency index [22]:

$$
\begin{gathered}
C_{1}=\frac{\beta-N}{N-1}, \\
\kappa=\frac{\eta}{\sum_{i=1}^{p} \omega_{i}} .
\end{gathered}
$$

Random consensus ratio:

$$
\mathrm{CR}=\frac{\mathrm{C}_{1}}{\mathrm{RT}}
$$

The $Z_{C}$ of the importance of tourism security risk assessment of smart scenic spots is [23]

$$
Z_{C}=\sum_{i=1}^{n} Q_{i} W_{i}
$$

(1) Application presentation layer: based on service as the premise and convenience for the people, it uses a variety of service methods to make the service respond to the demanding personnel in a timely manner and make the information more convenient. Mainly based on the development of various application systems including browsers, mobile office equipment, multimedia terminals, instant messaging tools, etc., it is the basic guarantee for the realization of the value of the minority smart tourism service platform.

(2) Core business application layer: based on the construction of various service applications and application support systems, it provides corresponding tourism service application functions to different user groups. It is the "core" of the ethnic minority smart tourism service platform and realizes various business functions key. The business application layer provides a wide range of tourism service applications. The business applications facing tourists mainly include information query services, smart guide applications, call center services, electronic map systems, travel complaint systems, ILBS location positioning services, voice navigation systems, alarm help system, online ticket booking application, etc. The business applications facing government departments mainly include OA office systems for platform management, information release systems, market business statistics applications, integrated security systems, passenger flow monitoring systems, data mining applications, emergency handling services, etc. Business applications for enterprises 
mainly include information uploading of tourism enterprises, online booking, e-commerce applications, advertising marketing applications, online ticketing applications, etc.

(3) Application support layer: cross-departmental and cross-system information exchange and sharing can be realized. Mainly include secondary development platform, online payment, log management, search engine, etc.

(4) Data resource layer: it is the database server, which is a comprehensive database system. It provides specifications for the business logic layer and realizes the full sharing of business data, which is the foundation of the entire system. Composed of basic database, system database, business database and other databases, it is the basic data support for various services and applications of smart tourism. Among them, the basic database contains basic tourism data in six major aspects of tourism, including food, accommodation, transportation, travel, shopping, and entertainment, including pictures, audio, video, and virtual tourism applications. The system database contains information technology development data and user registration data that need to be used in the construction of the platform to ensure the safe and stable operation of the platform and the collection of user information for visitors. Business data includes data generated by service applications provided by the platform, transaction data generated by e-commerce, geographic location data generated by GPS positioning, etc. Other databases include regulatory database, standard specification database, scenic spot security database, etc.

(5) Infrastructure layer: it include network communication (GSM, GMB, TS, WIFI, etc.), hardware equipment, storage equipment, security equipment, etc. Technology through all kinds of data collection and perception, such as RFID, bar code, sensors, and cameras.

The ethnic minority wisdom tourism service platform also requires the support of standard specification system and information security and operation management system in addition to each informatization construction part. In the construction of the minority wisdom tourism service platform, the standard specification is the important guarantee for the development of tourism informatization, and it is necessary to comply with relevant laws and regulations and criteria.

2.2.2. Technical Framework. As a product of the transformation and development of modern tourism to informatization, the minority smart tourism service platform will inevitably be inseparable from the support of modern information technology. The design of the minority smart tourism service platform in this paper adopts the J2EE platform, the B/S (Browser/Server browser/ server) model, and the SOA (Service-Orient Architecture) service-oriented architecture, the information exchange format is XIL, and the transmission network protocol is HTTP. The overall construction of the platform is based on Java technology, using the advantages of the B/S model, so that users can operate anywhere without installing any plug-ins. They can access and use various business functions simply by accessing the platform website, which can achieve zero installation. And because the minority smart tourism service platform involves a variety of functional modules and is widely connected to other enterprises and industry systems, the design adopts the SOA architecture design that can provide external web service interfaces, high flexibility, loose coupling, and can combine and share information.

2.2.3. Network Architecture. The intelligent tourism service of the minority people platform realizes the access of the different enterprise service resources and sharing them by means of data interface setting and network transmission and integrates the business under different platforms through Web Service technology. With the digital network of TCP/IP protocol, it is used in the platform network, which fully considers the security, stability, and reliability of Internet installation. Network equipment and facilities must conform to the principles of advancement and scalability. A complete network architecture design is the guarantee for the safe and effective operation of all systems on the platform. The network topology of the minority smart tourism service platform is shown in Figure 1.

2.2.4. Application System Architecture. The smart tourism public service application system must meet the three major requirements of different service objects. One is a smart service system aimed at satisfying tourists' travel information services. The second is to meet the needs of tourism companies for online marketing and e-commerce on the platform. The third is to provide a platform for the government to master travel information and supervise the travel market to realize e-government management. Therefore, the smart tourism application system includes three aspects: service, market, and management.

(1) Smart Tourism Service Module. It is a system that provides tourists with "eating, accommodation, transportation, travel, shopping, entertainment" tourism information inquiry and consulting services, and at the same time using modern information technology to provide navigation, tour guide, tour guide, and shopping guide services in tourism. It mainly includes tourism information service platform, e-commerce service platform, tourist complaint service platform, etc. Tourists can log in to the minority smart tourism service platform and use the platform to provide smart tourism service systems to obtain the information and tourism application services they want.

(2) Smart Tourism Marketing Module. It is the corporate product display, image promotion, and platform sales services provided by the platform for tourism companies. 


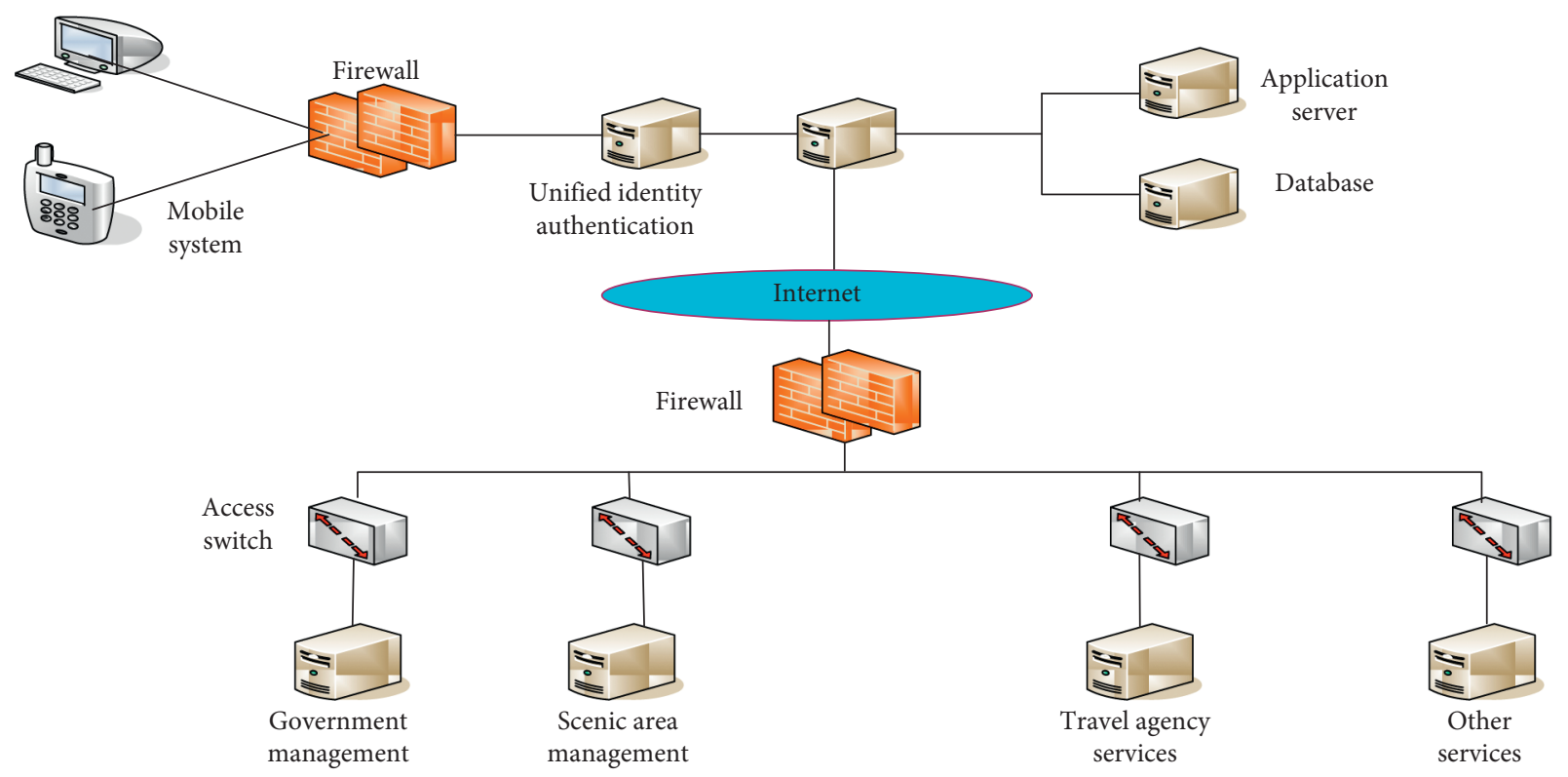

FIGURE 1: The network topology of the minority smart tourism service platform.

Hotels can realize hotel information promotion and display through the platform and directly carry out online booking, online payment, and other services through the third-party interface; scenic spots can provide tourism product display through the platform to achieve the marketing purpose of the scenic spot, and the platform supports online ticket booking, online payment, and travel all-in-one card registration, so that tourists who have booked tickets can directly enter the scenic spot with identification cards, travel cards, QR codes, and other identity verification information without queuing; travel agencies can display travel route design, travel product quotations, and other information through the platform, can realize online business acceptance, and can directly complete travel-related procedures; and travel shops and other travel product operating companies can use the platform online promotion module to increase the popularity and attractiveness of their travel products and improve product sales performance.

(3) Smart Tourism Management Module. Provided the tourism management department with services for managing various types of tourism information on the platform, platform safety operation, and emergency response system and better provide strong support for tourism management departments at all levels to fulfill their regulatory obligations and platform information management. The smart tourism management system helps the management department to manage tourism policies, tourism real-time information, emergency response, etc. Through the collection, integration, and analysis of a large amount of tourism data through the minority smart tourism service platform and the use of third-party interface data intercommunication, the sharing and supervision of tourism information can be realized, and the stable operation of tourism units at all levels can be provided.

\subsection{Design of Smart Service Application System}

2.3.1. System Composition. The Smart Travel Service Application System primarily provides massive travel information and compliance with the four major services of navigation, information guide, tour guide, and shopping guide from the perspective of viewers. This comprehensively includes all information services before, during, and after the journey.

2.3.2. Functional Design. Tourism Public Information Service Subsystem is the most important information service system provided by the platform to users. It provides tourists with online browsing and query services of travel information and unified notification services. The platform sets up data interfaces with other external tourism-related scenic spots, enterprises, and other systems and collects and unifies tourist information such as scenic spots, catering, and tourism products through data exchange, so as to provide tourists with real-time and effective travel information, and also improve tourists' travel information acquisition comprehensiveness and convenience. The tourism information resources of the platform mainly include real-time dynamic perception information such as traffic, weather, scenic spot introduction, tourism policy, and support multimedia information data such as pictures, audios, and videos. The tourism public information service subsystem mainly has the following functions:

(1) Search engine query: the system provides search information query services, and supports finding the target link address through keyword query. Users only need to $\log$ in to the platform portal, enter keywords and click "Search" to find the information they want. 
(2) Hot information display: the system provides a hotspot information display section, and the information content includes tourism hotspot information of provinces, cities, and regions and the latest tourism policies and regulations. Information is mainly displayed in the text form, but also supports multimedia forms such as pictures, audios, and videos, and supports hyperlinks.

(3) The latest activity guide: the latest activity guide mainly relies on the database server of each scenic spot in the system background. A large number of tourist scenic spots at home and abroad are collected in the database, such as scenic spot address, scenic spot introduction, and real-time latest activity guide of scenic spot. Users can independently choose the scenic spots they want to know and click to get the latest activity information provided by the platform.

(4) Unified notification service: the unified notification service is a reminder and notification service that the platform provides to users. When users conduct information interaction services such as user registration, online reservations, and online transactions on the platform, the platform provides SMS notification services and e-mail notification services. The notification service is sent to users in SMS or HTML encoding, and users can obtain information directly through SMS or click a link. It allows visitors to send platform registration and trading information via SMS or e-mail to enable online platform user for registration and order management via SMS as well as e-mail. This service includes SMS verification code, registration feedback information notification service, notifications for order management include online order code, and order details and other monitoring information in marketing. The scenic spot information is shown in Table 1 .

2.3.3. Smart Tour Guide Subsystem. The smart tour guide subsystem provided by the Minority Smart Tourism Service Platform is a system supported by mobile terminal devices. It can provide self-service tour guides, guided tours, and navigation services based on various geographic information data provided by the geographic information system (GIS). The system obtains the GPS positioning signal of the satellite through the user's mobile terminal equipment and sends the position information to the GIS system through data transmission. Because the GIS system can realize map browsing, dynamic query, and basic map operations, it provides modern technical support for navigation, tour guide, and navigation. The main functions of the intelligent tour guide subsystem are as follows:

(1) Online navigation service: the online navigation system is connected to the network in real time. The entire map data storage and path planning are completed on the platform server. Through data transmission, online navigation map information and route recommendations are finally formed on the user terminal. The online navigation service supports target location setting and navigation route calculation and display, and GPS service is required to provide the user's location data as the initial location. Online navigation services support map display, route planning, and geographic location search engines.

(2) Self-guided tour guide service: users can log in to the platform and click on the self-service tour guide service. The system will automatically obtain user geographic information from the user's mobile phone and automatically play tour guide audio and video data based on this. This function is technically supported by the GPS positioning system, and the guide information database is the data base (including guide audio data, historical introduction information of scenic spots, cultural information of scenic spots, etc.) to provide tourists with real-time guide services.

(3) Automatic guided tour service: an automated tour guide service also relies as well on GPS positioning technology, which is combined with $3 \mathrm{D}$ virtual technology. Through the acquisition of the user's geographic information, it can accurately locate and perceive the tourist attractions and explain the attractions actively before the tourists, providing a 3D virtual tour service for the display of real scenes and tourist guidance information for the visitors. The automatic navigation service is shown in Figure 2.

2.3.4. Interactive Communication Subplatform. The Minority Smart Tourism Service Platform is to facilitate communication between tourists and provide a platform for asking questions and answering doubts. The platform has two main functions, namely:

(1) Travel Q\&A: travel Q\&A is an online question answering section set up by the interactive communication platform. Tourists can submit their questions during their travels by clicking on the "Travel Q\&A" section. The platform can provide a standard question publishing format, and visitors upload their own questions by filling in the questions. This section will have dedicated service personnel to collect and feedback questions, support real-time or next-day reply, and support the push and online display of reply information.

(2) Interactive forum: the interactive forum is an exchange platform for visitors to display travel notes sharing, photography sharing, and online interaction. Visitors can log in and click to enter the interactive forum, edit information in the corresponding editing section, and share their travel experience and travel information in real time. The interactive forum supports the uploading and downloading of texts, pictures, videos, and other forms of information. Through online communication, tourists can make like-minded friends, share travel insights, and even broaden the resources of tourist destinations. 
TABLE 1: Scenic area information.

\begin{tabular}{lccc}
\hline Field name & Length & Allow empty & Describe \\
\hline JQBH & 4 & No & Scenic spot number, primary key, self-increment \\
JQMC & 50 & No & Scenic name \\
ZH & 20 & Yes & Administrator account \\
MM & 128 & Yes & Administrator password \\
SZDQ & Default & No & Area code, foreign key \\
JQJJ & 200 & No & Scenic introduction \\
JQTP & 20 & No & Scenic image, save the file path of the scenic image \\
\hline
\end{tabular}

2.3.5. Tourist Complaint Service Subplatform. The construction of the tourism complaint service subplatform allows tourists to complain about dissatisfaction with scenic spots and tourism activities during and after traveling through various user terminals and to track complaints handling.

The tourist complaint service platform also provides customer service complaints, 12,301 complaint hotline, national smart tourism public service WeChat official account, and other complaint methods. It is up to the user to choose the complaint channel that he or she thinks is convenient.

\subsection{Smart Management Application Module Design}

2.4.1. Module Composition. With the building of smart tourism management application module, we have provided basic guarantee for real-time data update and response for the intelligent tourism service platform of minority groups, which enables the analysis and sharing of information data of as a whole tourism industry, contributes to the strengthening of tourism property alliance, and improves the regulatory ability of provincial government offices. The system module includes an information collection and release system, an information integration analysis platform, and an emergency response system. The information of tourism management department is shown in Table 2.

\subsubsection{Functional Design}

(1) Tourism information collection and release module: an important application system that the platform management department has for information management of the minority intelligent tourism service platform is the information collection and release module. Through the interfacing with other third-party systems such as video monitoring, as well as environmental monitoring and emergency respond platform, the system collects real-time information and extracts real-time information such as visitor flow, client data, environmental information, scenic area-related information on unexpected events, and real-time information on national tourism in policy. And through the information release system to release dynamic travel information to various user terminals (websites, mobile phones, media screens, etc.). Figure 3 shows the collection and release of tourism information.

(2) Integrated video supervision module of scenic spots: the minority smart tourism service platform must be connected with the establishment of a comprehensive video supervision system for scenic spots and provide real-time retrieval and viewing functions of all scenic spots videos, so that managers can directly supervise the safety of scenic spots through the platform and implement corresponding safety prompts. The surveillance range of the scenic spot video surveillance system must cover the scenic traffic arteries, scenic entrances and exits, key protected areas and areas with high accidents, and support long-term surveillance data storage. The establishment of the scenic spot video supervision system can make the work management more scientific, precise, intelligent, and informatized and can enable managers to intuitively manage various affairs in each scenic spot through the platform. The scenic video integrated supervision system is connected to the internal platforms of each scenic spot through the TCP/IP protocol, so that the system can obtain the resources of each subsystem through system connection and data exchange and can perform realtime management operations $[24,25]$.

(3) System analysis subplatform: the statistical analysis platform includes system traffic statistics, system investigation, and analysis. Through the collection, analysis, sorting, and sharing of user access data, tourism companies can provide targeted and personalized service construction and make tourism services smarter and more scientific. Among them, the system traffic statistics system is based on the platform visits, statistical analysis of visiting IP addresses, search keywords, and clicks on functional applications, to determine the influence of the platform and the attention of visitors. The focus and the preference of visitors can be used for tourism companies and tourism. Platform managers provide databases. The platform can automatically establish data management, store data according to information classification, support the automatic generation of various charts, and realize the analysis of user preferences [26]. 


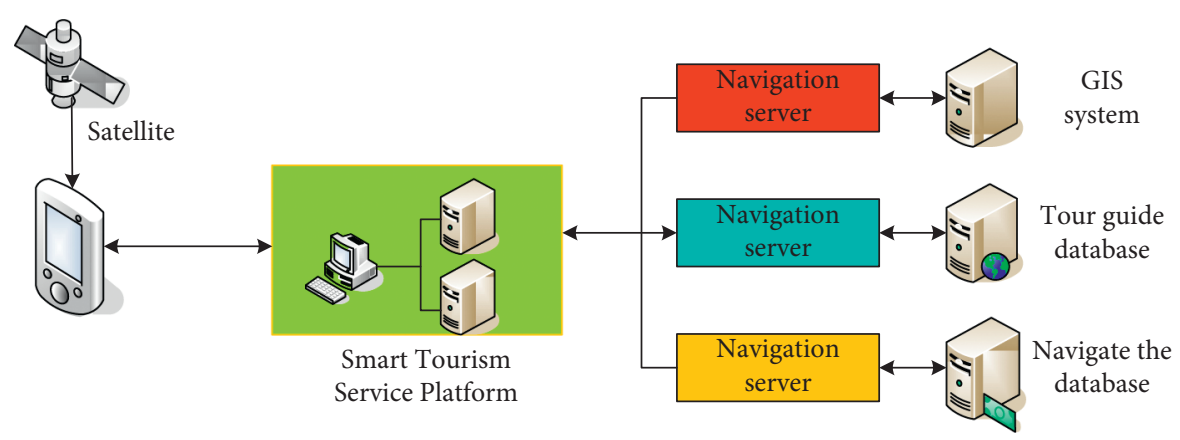

FIGURE 2: Automated navigation service.

\section{Results}

The vegetation coverage rate in the minority wisdom scenic area of $\mathrm{M}$ city is relatively large, with abundant species of animals and plants and obvious vegetation distribution. From the foot of the mountain to the top of the mountain, different vertical landscape belts with different communities are formed at different heights. The characteristics of the vertical natural belts in the smart scenic area of $M$ city are shown in Table 3.

The ability and quality of service personnel in the scenic area are also factors that may cause security risks in the scenic area. The service attitude, service skills, and level of the service personnel in the scenic area directly or indirectly affect the safety of tourists. A large part of the sanitary problems experienced by tourists in the travel process such as accommodation and catering are due to deviations in the service skills of service personnel. Compared with the professional service personnel, their service awareness and safety awareness are not very strong. The ability and quality of service personnel have a certain relationship with the degree of education they receive. The ability and quality of personnel with relatively high education level are relatively high. The statistics of service personnel in the scenic area are shown in Table 4.

Smart tourist attractions have not been established in my country for a long time, and they have not accumulated enough experience. Therefore, it is necessary to rely on relevant experts in the tourism field to compare the importance of primary risk factors and secondary risk factors to the total risk factors. The discriminant matrix is shown in Table 5 .

Based on the investigation and analysis of ethnic minority foreign tourists, combined with the data analysis results of the online questionnaire survey, 172 questionnaires were distributed online, 164 were retrieved, and 161 valid questionnaires were collected. The male to female ratio of the target user population is $54.55 \%$ for girls and $45.45 \%$ for boys. The research and analysis ratio is shown in Figure 4.

As shown in Figure 5, freelance and students account for a larger proportion of tourist occupations, and other occupations also account for a large proportion. Freelance entrepreneurs have irregular working hours and are relatively free in travel time. Students have regular winter and summer vacations every year, and relatively speaking, they have ample travel time, which creates good conditions for travel. The occupation of tourists is shown in Figure 5.

The target user population of tourism is mainly young people and above, and the age range is mainly from 19 to 40 years old. The age distribution of tourist target users is shown in Figure 6.

In recent years, $\mathrm{m}$ city received 73.3581 million domestic and foreign tourists in 2020, an increase of $19.41 \%$ over 2019 . Among them, overnight tourists received 34.6944 million person times, an increase of $21.45 \%$ year-on-year in 2019 . In the whole year, the total tourism revenue was 62.378 billion yuan, an increase of $21.86 \%$ year-on-year in 2019. See Figure 7 for details.

In the survey results, $39.09 \%$ of tourists are interested in ethnic minority food, and some tourists are interested in ethnic minority buildings and costumes and intangible cultural heritage. These indicate from the side that intangible cultural heritage has left a place in the hearts of tourists. Tourists' preferences for ethnic minorities are shown in Figure 8.

The tourism platform design login and registration interface background adopt ethnic blue as the background color and make full use of the shading to create a national atmosphere, strengthen its cultural immersion, and let users feel the charm of ethnic minorities in the process of logging in and registering. The font color adopts white and blue to form a strong contrast with the background, focusing on the text information. The eye-catching logo at the top of the interface echoes with the content of the APP design and fully demonstrates the design theme of the ethnic cultural tourism platform, as shown in Figure 9.

According to the data, the tourist destinations of residents in M City have undergone tremendous changes from 2011 to 2018. Beginning in 2011, the number of people in $\mathrm{M}$ City who use leisure and vacation as their tourism purpose has continued to increase. After 2016, there was a huge increase, accounting for $50.1 \%$ of the total number of people, and it dropped slightly to $48.3 \%$ in 2018 . From the data of City $\mathrm{M}$ alone, the city's total tourism revenue in 2020 will reach 75.68 billion yuan, a year-on-year increase of $21.33 \%$, of which foreign exchange income is US\$886 million, a yearon-year increase of $33.56 \%$. The sustainable development of the tourism industry provides a good economic environment for the construction of smart tourism. Coupled with government subsidies, infrastructure construction is easy to 
TABLE 2: Tourism management department information.

\begin{tabular}{lccc}
\hline Field name & Length & Allow empty & Describe \\
\hline BMBH & 4 & No & Department number, primary key, self-increment \\
BMMC & 50 & No & Department name \\
GLYZH & 20 & Yes & Administrator account \\
GLYMM & 128 & Yes & Administrator password \\
LXDH & 20 & No & Contact number \\
FGDQ & 4 & No & In charge of area code, foreign key \\
CFQX & 1 & No & Punishment authority, $0:$ none; $1:$ yes \\
\hline
\end{tabular}

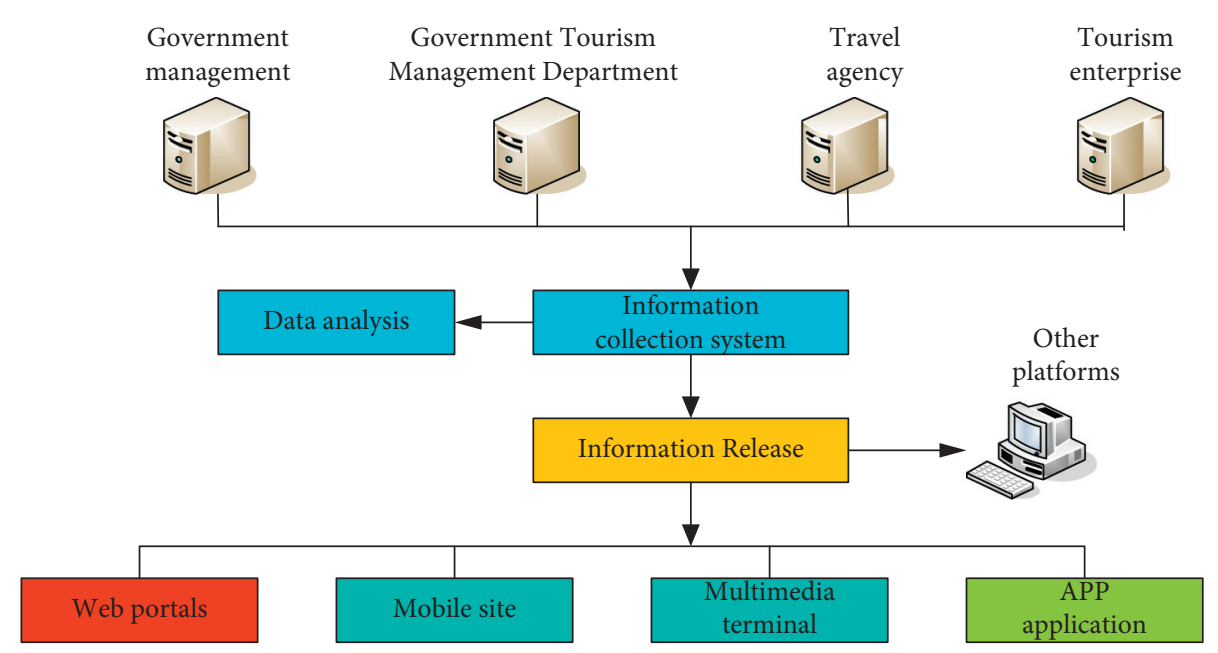

Figure 3: Collection and release of tourism information.

complete. It can also complete the upload of information and data, but most small-scale tourism, especially with the development of rural revitalization, various pastoral complexes, ancient villages are small in scale, and the tourism business is relatively single. It is difficult to complete the integration of technology and industry. Smart tourism applications are aimless, software cannot be connected to the platform, and it is difficult to form data analysis after being connected to the platform in time and provide constructive data for later construction. The income of City M is shown in Figure 10.

\section{Discussion}

The ethnic minorities have a gathering of humanities, and the development of ethnic minority culture has become more and more mature in the long years. At present, the culture of ethnic minorities is gradually disappearing and sinicized. Many intangible cultural heritages are on the verge of uninherited and unknown crisis. It is urgent to strengthen the public's awareness of ethnic minority cultures [27].

If the economic benefits brought by the implementation of the smart tourism system can be greater than the development cost of the system, it is feasible. The construction cost of the smart tourism system includes the purchase of hardware and software systems, geographic information systems (GIS), personnel costs, and publicity costs. According to the scale of the construction of the smart tourism system, the cost is between several million yuan and ten million yuan. Although the system investment is high, the investment in the smart tourism system is worthwhile from a sustainable perspective. After the completion of the smart tourism construction, it will bring the following benefits: publicize tourism, increase passenger flow, make full use of the resources of the tourism province, and drive the economy development; increase the income of other subsidiary industries, and the increase in passenger flow will inevitably drive the income of a series of subsidiary industries; the reduction of personnel costs, the use of smart tourism information systems can not only improve the passenger experience but also reduce the cost of personnel in the tourism industry. Therefore, in the long run, the smart tourism information system is sustainable in terms of economic benefits [28].

Smart tourism information system should not be designed only for tourists. Smart tourism is a combination of cloud computing, Internet of Things, mobile communication technology, and artificial intelligence technology. It is important for tourists to display information, but at the same time, the collection and processing of information are equally important. It can add fresh blood to the smart tourism information system, maintain the real-time, accuracy, and sustainability of the information of the smart tourism information system, so as to better serve tourists and further promote the sustainable development of the tourism industry. The design of a smart tourism information system should not only be aimed at 
TABLE 3: Vertical natural belt characteristics of smart scenic spots in M City.

\begin{tabular}{lcc}
\hline Name & Altitude & Representative plants \\
\hline Artificial and semiartificial vegetation zone & $800-1000 \mathrm{~m}$ & Hawthorn, hickory, chrysanthemum, poplar, willow, elm \\
Low mountain shrub zone & $1000-1300 \mathrm{~m}$ & Maozhen-lilac Duancong \\
Birch and oak forest belt & $1300-1600 \mathrm{~m}$ & Accompanied by a small amount of willow \\
Birch Forest Belt & $1600-1850 \mathrm{~m}$ & There are a small amount of colored maple and linden tree \\
\hline
\end{tabular}

TABLE 4: Statistics of service personnel in scenic spots.

\begin{tabular}{lcc}
\hline Education & Number of people & Average T capital \\
\hline Technical secondary school and below & 402 & 2516 \\
Junior college & 99 & 3078 \\
College degree or above & 53 & 3630 \\
\hline
\end{tabular}

Table 5: Discriminant matrix.

\begin{tabular}{lccc}
\hline Matrix & H1 & H2 & H3 \\
\hline H1 & 1 & $1 / 2$ & $1 / 3$ \\
H2 & $1 / 2$ & 1 & $1 / 5$ \\
H3 & $1 / 3$ & $1 / 3$ & 1 \\
\hline
\end{tabular}

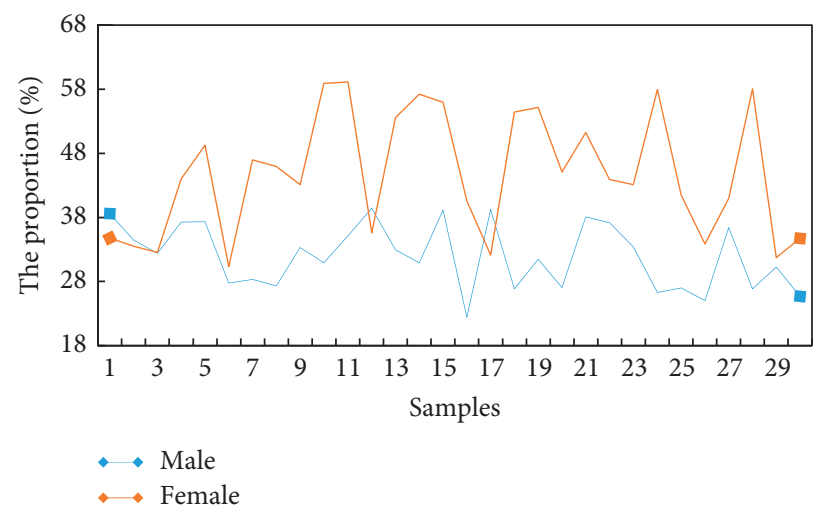

FIgURE 4: Research and analysis ratio.
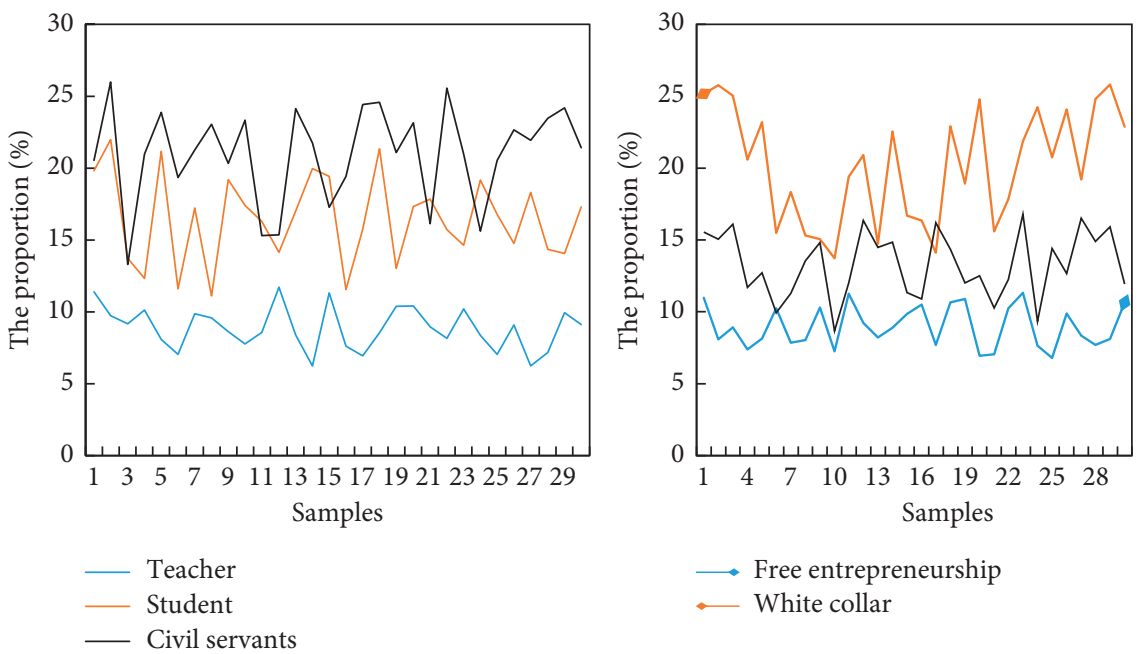

Figure 5: Occupation of tourists. 

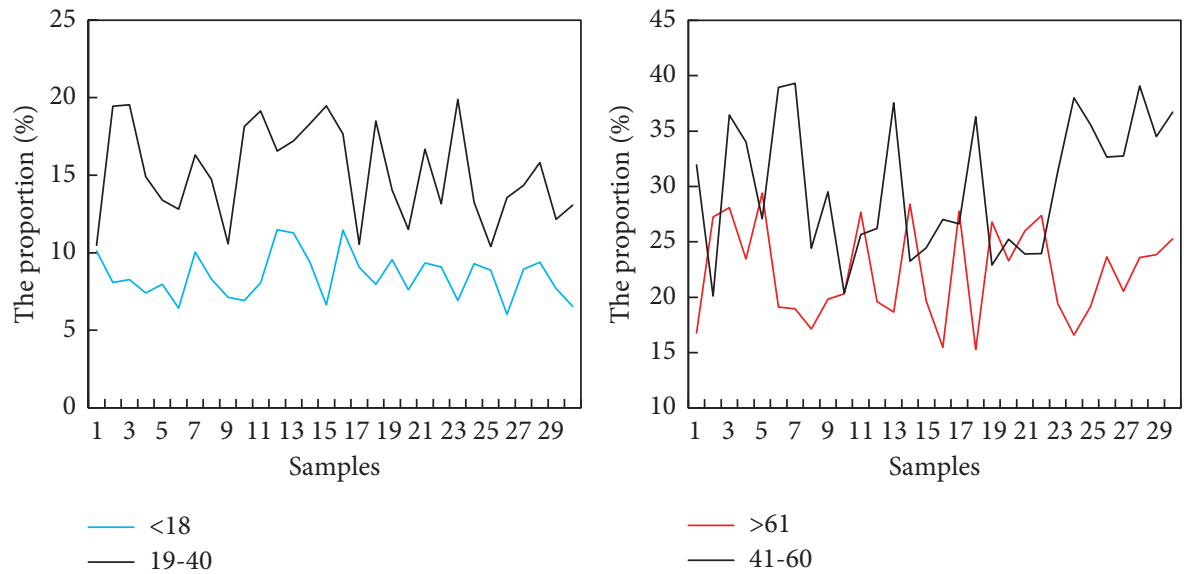

Figure 6: Age distribution of tourism target users.

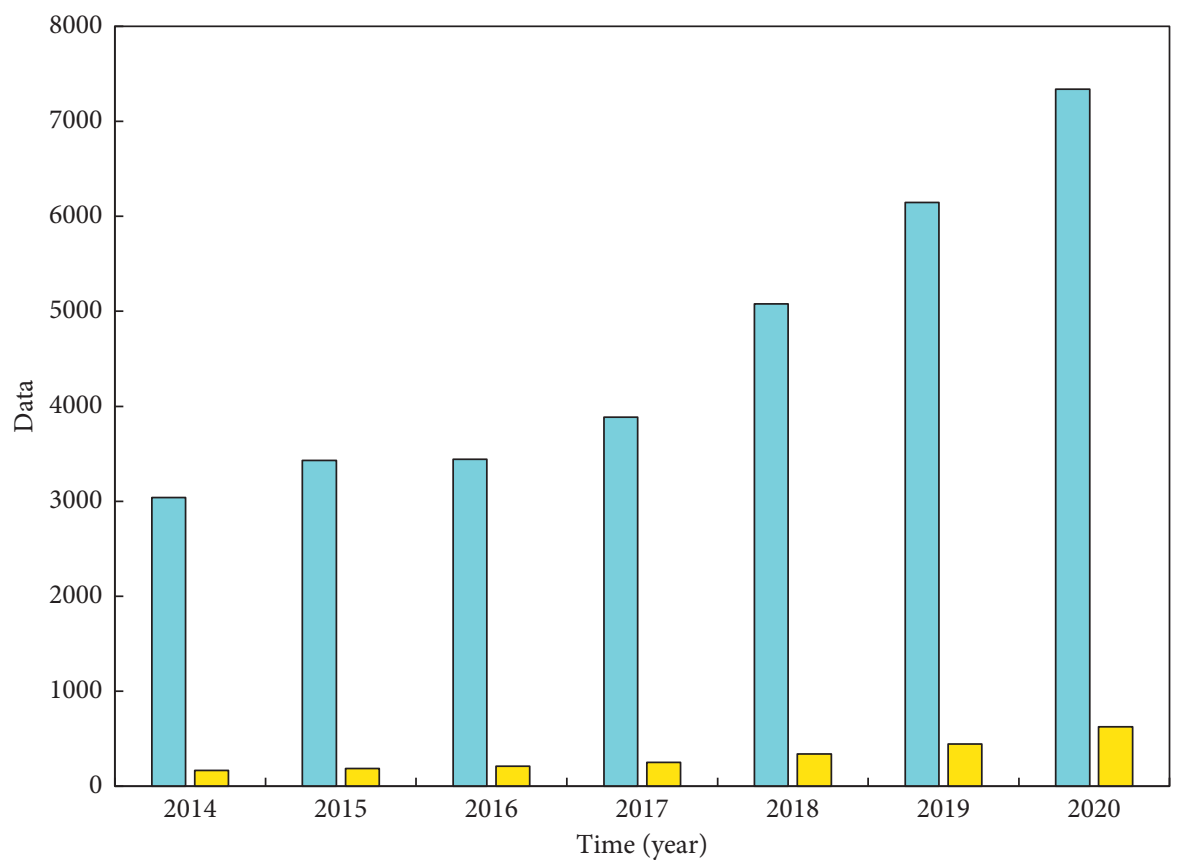

Number of Tourists Received by Scenic Spots (Ten thousand people)

Tourism income (100 million yuan)

Figure 7: The specific situation.

tourists. Tourism management departments, scenic spots, tourism companies, hotels, etc. should all participate in information interaction, management, or commercial competition. This is bound to have a positive effect on the sustainable development of smart tourism. The role of promotion also has a certain effect on the sustainable development of smart cities. At the same time, the medium of information collection and display of the smart tourism information system should not be limited to mobile devices. Combining personal PCs, smart tourism WEB website construction, scenic spot multimedia query systems, scenic spot LED query systems, telephone queries, short message services, etc., can promote diversified development of urban smart tourism that facilitates the participation of tourists and smart tourism-related departments or personnel and ultimately attracts more tourists with its convenience and promotes the sustainable development of tourism [29]. 


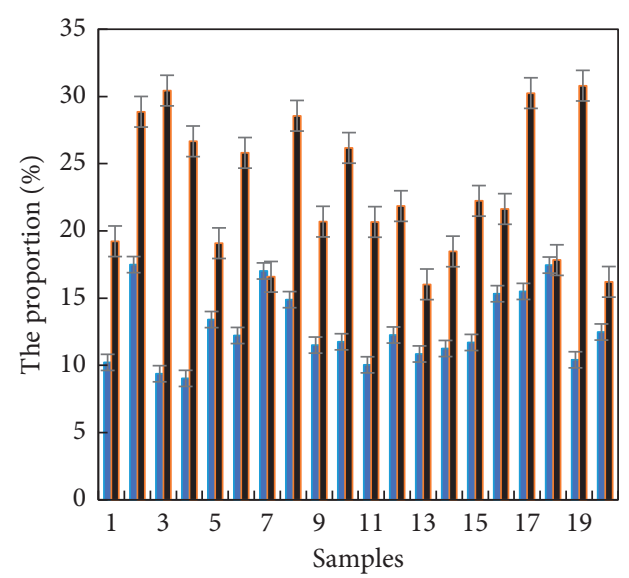

Architecture Apparel

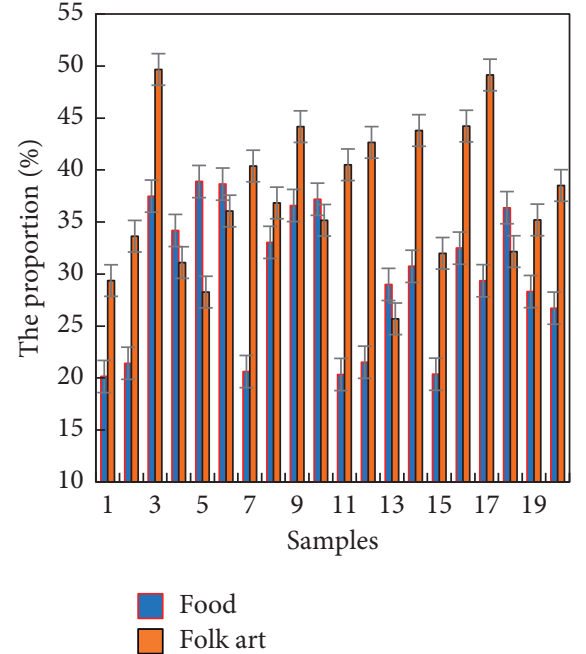

$\square$ Folk art

Figure 8: Tourists' preferences for ethnic minorities.

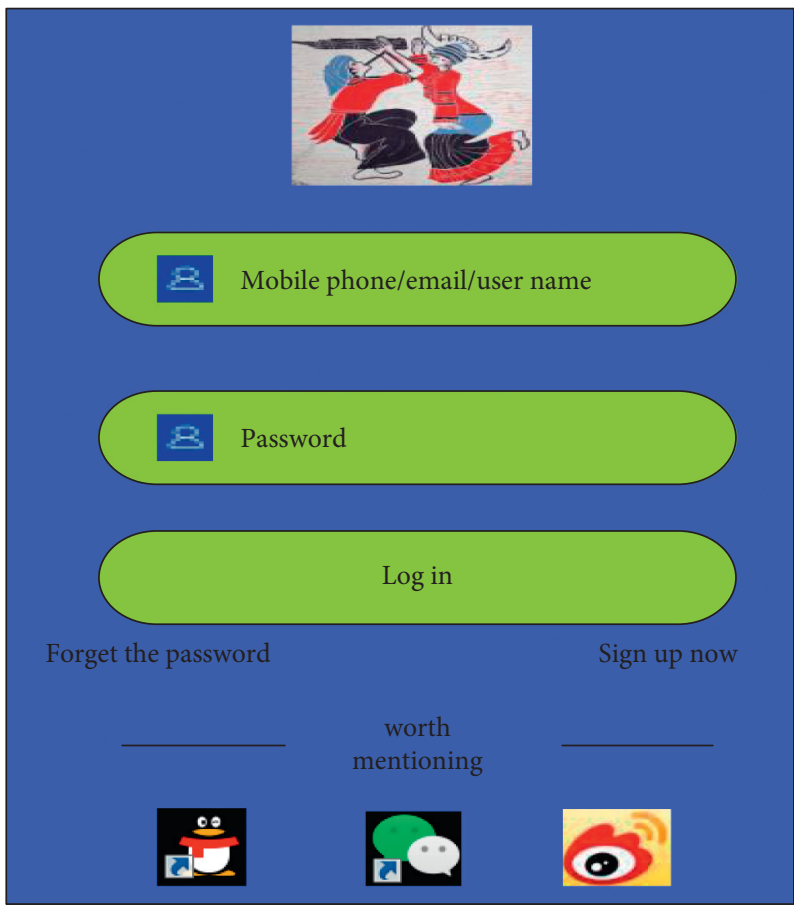

FIGURE 9: The interface of ethnic minority cultural tourism platform.

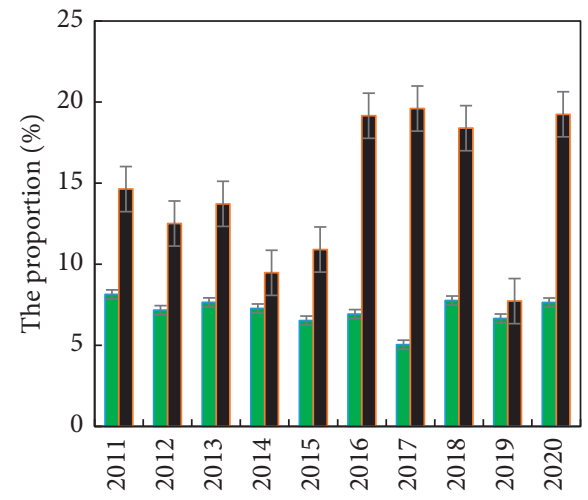

Time (year)

Growth rate

Permeability

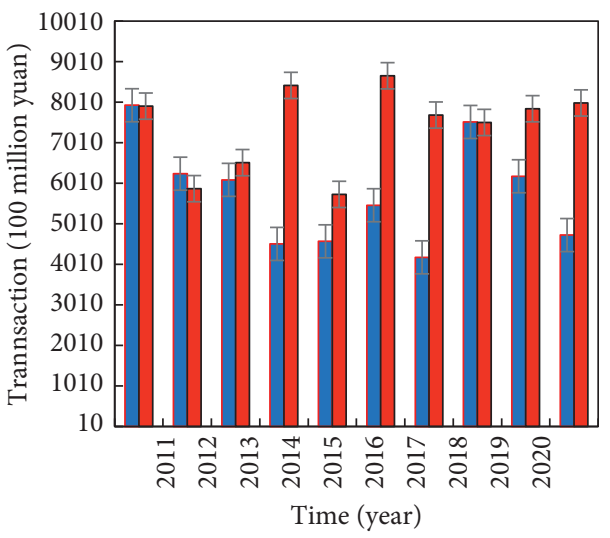

Online transaction

Offline transactions

Figure 10: Income of City M. 


\section{Conclusion}

This study connects the smart city with the construction of ethnic minority tourism information service system, fills the research gap in the integration, systematization, and intelligence of urban ethnic minority tourism information service system, and puts forward the cutting-edge ideas and research direction of urban ethnic minority tourism service system. Through the typical cases of the construction of minority tourism information service system in smart cities, combined with the analysis and comparison of questionnaires facing the needs of tourists, a set of intelligent promotion system theory of tourism cities based on tourists' satisfaction and taking tourism information processing and dissemination as the main line is formed. This study is based on the needs of minority tourism information services serving tourists, especially individual tourists, to drive and standardize the construction of tourism minority service system and promote the transformation and upgrading of tourism industry. In the future, tourism will promote development and promote the overall wisdom of tourism cities through the construction of smart tourism minority service system.

\section{Data Availability}

The data that support the findings of this study are available from the corresponding author upon reasonable request.

\section{Conflicts of Interest}

The authors declare no potential conflicts of interest with respect to the research, authorship, and/or publication of this article.

\section{Acknowledgments}

This research was funded by the Heilongiiang Province Art Science Planning Key Project: Research on the Protection of Minority Culture and Art and Tourism Development in Heilongjiang River Basin (Item number: 2020A026).

\section{References}

[1] M. Mohamad, N. I. Ab Ghani, and M. N. Muhamad Nasir, "The impact of perceived value, destination service quality, and tourist satisfaction on destination loyalty among international tourists visiting Malaysia," Journal of Tourism, Hospitality and Environment Management, vol. 4, no. 16, pp. 10-26, 2019.

[2] N. Nenkov, O. Sushchenko, and Y. Dyachenko, "Role of chief information officer within the system of human resource development in service organizations (tourism)," Economic Annals-XXI, vol. 165, no. 5-6, pp. 97-103, 2017.

[3] T.-E. Cheng, J. Wang, D.-J. Zhang, and M.-M. Cao, "TODIM method for evaluating the service quality of boutique tourist scenic spot with 2-tuple linguistic information," Journal of Intelligent and Fuzzy Systems, vol. 37, no. 2, pp. 2075-2083, 2019.

[4] C. Wei, Q. Wang, and C. Liu, "Research on construction of a cloud platform for tourism information intelligent service based on blockchain technology," Wireless Communications and Mobile Computing, vol. 2020, no. 2, pp. 1-9, 2020.

[5] I. F. Ashari, "Implementation of cyber-physical-social system based on service oriented architecture in smart tourism," Journal of Applied Informatics and Computing, vol. 4, no. 1, pp. 66-73, 2020.

[6] G. Tang and H. Zeng, "Evaluation of tourism E-commerce user satisfaction," Journal of Organizational and End User Computing, vol. 33, no. 5, pp. 25-41, 2021.

[7] R. Filda, N. Akmaliah, M. Hariri, I. Yunita, and A. Grace, "Tourism service quality and tourism product availability on the loyalty of international tourists," Journal of Asian Finance Economics and Business, vol. 7, no. 12, pp. 959-968, 2020.

[8] L. Setiorini, "The analysis of grammatical errors spoken by malang tourist information center's customer services," Jurnal Ilmiah Bahasa dan Sastra, vol. 4, no. 2, pp. 125-130, 2019.

[9] G. Alhammadi, S. Bourekkadi, and S. Khoulji, "Conception of a computer application for improvement of tourism service in Morocco," International Journal of Pure and Applied Mathematics, vol. 120, no. 6, pp. 2931-2957, 2018.

[10] B. B. Gupta, P. Chaudhary, and S. Gupta, "Designing a XSS defensive framework for web servers deployed in the existing smart city infrastructure," Journal of Organizational and End User Computing, vol. 32, no. 4, pp. 85-111, 2020.

[11] N. L. Meyoki and L. Kavindah, "Exploration of adoption of information communication technology by tourist camps in Maasai Mara, Narok county, Kenya," International Journal of Current Aspects, vol. 3, no. VI, pp. 291-308, 2019.

[12] I. M. P. Mertha, V. Simadiputra, E. Setyawan, and S. Suharjito, "Implementasi WebGIS untuk Pemetaan Objek Wisata Kota Jakarta Barat dengan Metode location based service menggunakan Google maps API," InfoTekJar (Jurnal Nasional Informatika dan Teknologi Jaringan), vol. 4, no. 1, pp. 21-28, 2019.

[13] S. Araya-Pizarro and M. Álvarez Cortés, "Characterization of the national and foreign tourist who visits the city of La Serena, Chile," Revista Interamericana de Ambiente y Turismo, vol. 16, no. 1, pp. 49-65, 2020.

[14] Y. Li, "Design and implementation of intelligent travel recommendation system based on internet of things," Ingénierie des Systèmes d'Information, vol. 23, no. 5, pp. 159-173, 2018.

[15] I. A. Kiseleva, N. E. Simonovich, A. V. Litvinova, and Y. A. Shapovalov, "Innovation risks in the market of tourist services," Proceedings of the Voronezh State University of Engineering Technologies, vol. 79, no. 4, pp. 344-349, 2018.

[16] C.-A. Chen and H.-L. Lee, "How to promote bike tourism globally," Tourism and Hospitality Management, vol. 23, no. 1, pp. 1-16, 2017.

[17] P. C. Reyner, G. V. Gelmar, R. A. Sánchez, and V. R. Martínez, "Quality management and customer satisfaction in a tourist destination, a structural equation analysis," Polish Journal of Management Studies, vol. 16, no. 1, pp. 175-186, 2017.

[18] K. Staneva, "Cultural heritage and mineral springs-resources for the development of local tourist product," Knowledge International Journal, vol. 28, no. 7, pp. 2485-2490, 2018.

[19] L. T. Tung, "Forecasting the foreign tourist arrivals to Vietnam using the autoregressive integrated moving average method," Journal of Environmental Management and Tourism, vol. 9, no. 6, pp. 1135-1144, 2018.

[20] J. Micic, S. Denda, and M. Popescu, "The significance of the risk-related challenges in tourist destination choice," Journal of the Geographical Institute Jovan Cvijic, SASA, vol. 69, no. 1, pp. 39-52, 2019. 
[21] Z. Stefan and J. Pekovi, "Cultural intelligence and heritage impact on choosing foreign tourist destination," Menadzment U Hotelijerstvu i Turizmu, vol. 9, no. 1, pp. 27-42, 2021.

[22] S. H. Shon, "The effects of local culture festival program on visitors' satisfaction and purchase attitude-focusing on Yeoju ceramic festival -," Journal of the Korean Society Design Culture, vol. 23, no. 2, pp. 335-347, 2017.

[23] J. M. Cheer and A. A. Lew, "Sustainable tourism development: towards resilience in tourism," Interaction, vol. 45, no. 1, pp. 10-15, 2017.

[24] P. C. Morales, F. O. Agüera, T. López-Guzmán, and S. M. Cuadra, "Community attachment and support for sustainable tourism development through the attitudes of the local population: a case study in Puerto Plata, Dominican Republic," Mediterranean Journal of Social Sciences, vol. 9, no. 2, pp. 173-184, 2018.

[25] X. Zhu, "Self-organized network management and computing of intelligent solutions to information security," Journal of Organizational and End User Computing, vol. 33, no. 6, pp. 1-16, 2021.

[26] D. Streimikiene, B. Svagzdiene, E. Jasinskas, and A. Simanavicius, "Sustainable tourism development and competitiveness: the systematic literature review," Sustainable Development, vol. 29, no. 1, pp. 259-271, 2021.

[27] S. K. Gupta, S. Tiwari, and M. Voda, "Stakeholders' satisfaction towards sustainable tourism development in Pushkar region of Rajasthan," Geographia Technica, vol. 16, no. 1, pp. 87-96, 2021.

[28] V. M. Hieu, T. M. Lam, and S. Prabhakaran, "Perceptions of key stakeholders towards sustainable tourism development: a case study in Mekong delta, Vietnam," Journal of Asian Finance Economics and Business, vol. 8, no. 4, pp. 717-726, 2021.

[29] M. Ioannou and N. Boukas, "Co-creating visitor experiences in cultural heritage museums: the avenue towards sustainable tourism development," International Journal of Tourism Policy, vol. 10, no. 2, pp. 101-122, 2020. 